\title{
Bioquímica sérica e hemograma de bovinos antes e após a técnica de biópsia hepática
}

\author{
Serum chemistry profile and complete blood count in cattle before \\ and after liver biopsy technique
}

\section{Rogério Martins Amorim ${ }^{1}$ Alexandre Secorum Borges ${ }^{2}$ Márcio Rubens Graf Kuchembuck $^{3}$ Regina Kiomi Takahira $^{4}$ Nayro Xavier Alencar ${ }^{5}$}

\section{RESUMO}

\begin{abstract}
Avaliaram-se os efeitos da técnica de biópsia hepática sobre as atividades séricas das enzimas gama glutamil transferase (GGT), aspartato amino transferase (AST), fosfatase alcalina (FA), hemograma e fibrinogênio em 36 novilhas Nelore. Os animais foram submetidos ao procedimento de colheita de fragmento hepático, utilizando-se agulha de biópsia para determinação dos elementos minerais. As avaliações da bioquímica sérica foram realizadas em 20 novilhas, sendo divididas em dois grupos. No grupo $1(n=10)$, colheu-se sangue em tubos a vácuo sem anticoagulante, antes da realização da biópsia e 24 após, e no grupo $2(n=10)$ antes da biópsia e $96 h$ após. Os valores do hemograma e do fibrinogênio foram obtidos antes e $96 \mathrm{~h}$ após a realização do procedimento $(n=16)$. A atividade sérica da AST aumentou significativamente $(54,4 \%)$ $24 h$ após a realização da biópsia, porém estava dentro dos valores de referência $96 \mathrm{~h}$ após o procedimento. As atividades séricas da GGT e da FA não sofreram aumentos nas $24 \mathrm{~h}$ e $96 \mathrm{~h}$ após a biópsia. A proteína total apresentou aumento significativo de 0,24g/dL $96 \mathrm{~h}$ após o procedimento. Os demais parâmetros avaliados permaneceram dentro dos valores normais para a espécie. Os resultados obtidos permitem concluir que a técnica de biópsia hepática empregada é segura e eficaz por não provocar dano hepático significativo e por obter rapidamente fragmentos adequados para análise bromatológica e histopatológica.
\end{abstract}

Palavras-chave: agulha de biópsia, minerais.

\section{ABSTRACT}

The effects of liver biopsy technique on GGT (gama glutamil transferase), AST (aspartate amino transferase), FA (alcaline transferase) serum activity, complete blood counting and fibrinogen were evaluated in 36 Nelore breed heifers. The animals were submitted to liver biopsy, using biopsy needle for mineral element determination. The biochemical profile evaluation were obtained in 20 heifers, being divided in two groups. In group $1(n=10)$, blood was obtained with vacuum tubes without anticoagulant before and $24 \mathrm{~h}$ after biopsy, while in group $2(n=10)$ before and $96 \mathrm{~h}$ after biopsy. The complete blood count and fibrinogen values were obtained before and $96 h$ after biopsy $(n=16)$. The AST serum activity increased (54.4\%) 24 h after biopsy, but was within normal range after 96h. The GGT and FA serum activity did not increase $24 \mathrm{~h}$ and $96 \mathrm{~h}$ after biopsy. The total serum protein showed increase of $0.24 \mathrm{~g} / \mathrm{dL} 96 \mathrm{~h}$ after biopsy. The others parameters evaluated were within normal range for the species. The results allowed to conclude that the liver biopsy technique used shows safety and efficiency as it has not caused significant liver injury and has obtained fragments suitable for bromatologic and histopathologic analyses promptly.

Key words: biopsy needle, minerals.

\section{INTRODUÇÃo}

Os desequilíbrios minerais em bovinos afetam a homeostase de diversos sistemas orgânicos, prejudicando o ganho de peso e predispondo os animais às afecções. $\mathrm{O}$ estudo desses desequilíbrios exige o conhecimento do estado de nutrição mineral e de sua disponibilidade orgânica. A biópsia hepática em bovinos tem uma importante aplicação clínica, pois

'Professor assistente, Doutor, Departamento de Clínica Veterinária da Faculdade de Medicina Veterinária e Zootecnia (FMVZ), Universidade do Estado de São Paulo (Unesp-Botucatu), Distrito de Rubião Junior, 18618-000, Botucatu - SP. E-mail: rogerma@terra.com.br. Autor para correspondência.

${ }^{2}$ Professor Assistente, Doutor, Departamento de Clínica Veterinária, FMVZ-Unesp-Botucatu.

${ }^{3}$ Professor Titular, Departamento de Clínica Veterinária, FMVZ-Unesp-Botucatu.

${ }^{4}$ Professora Assistente, Doutora, Departamento de Clínica Veterinária, FMVZ-Unesp-Botucatu.

${ }^{5}$ Doutorando do Departamento de Clínica Veterinária, FMVZ-Unesp-Botucatu. 
fornece aos profissionais informações sobre a estrutura morfológica e sobre a composição bromatológica do órgão.

IVERSEN \& ROHOLM (1939) foram os pioneiros na descrição da técnica de biópsia hepática por aspiração em humanos. DICK (1944) adaptou a técnica de IVERSEN \& ROHOLM (1939) para estudar a concentração de cobre hepático em ovinos na Austrália. GARNER (1950), na Inglaterra, provavelmente foi o primeiro a adaptar o método para bovinos, baseando-se nos trabalhos de DICK (1944). LOOSMORE \& ALLCROFT (1951) realizaram biópsia hepática em bovinos e concluíram que este método apresentava vantagens em relação ao descrito por DICK, (1944) e GARNER, (1950), por não atravessar a cavidade torácica e o animal ser mantido em estação. $\mathrm{O}$ instrumento utilizado por esses autores tinha $18 \mathrm{~cm} \mathrm{de}$ comprimento, $0,4 \mathrm{~cm}$ de diâmetro interno, $0,5 \mathrm{~cm}$ de diâmetro externo com uma extremidade cônica e a outra adaptável a uma seringa de $20 \mathrm{~mL}$. A agulha de biópsia era introduzida no espaço intercostal entre a $11^{\underline{0}}$ e $12^{\underline{0}}$ costelas do lado direito, cerca de $17 \mathrm{~cm}$ abaixo da linha dorsal, obtendo-se amostras com peso entre 0,4 a 1,5g. A partir de 1951, foram publicados trabalhos descrevendo as variações da técnica de biópsia hepática nos animais domésticos. Dentre eles, destacam-se os experimentos de UDALL et al. (1952), SEGHETTI \& MARSH(1953), BONE (1954), ERWIN et al. (1956), ANDERSON et al. (1962), HUGHES (1962), CHAPMAN et al. (1963), FICK et al., (1979), PEARSON \& CRAIG (1980), SIMPSON (1985), SMART \& NORTHCOTE (1985), BUCKLEY et al. (1986), WITHEHAIR et al. (1988) e McDOWELL (1999). Esses autores descreveram modificações no instrumento de biópsia (dimensões e sistema de corte do tecido hepático), do local de penetração na parede torácica $\left(10^{0}, 11^{0}\right.$ ou $12^{\underline{0}}$ espaços intercostais, em diferentes alturas), do direcionamento dentro do abdômen (cranial ou caudal) e da pressão negativa produzida na agulha (por seringa ou tampando o orifício com o dedo).

CHAPMAN et al. (1963) repetiram o procedimento de biópsia hepática a cada 28 dias em um mesmo animal, durante dois anos, sem observar prejuízos ao desenvolvimento corporal. Os autores citados demonstraram que a técnica de biópsia hepática é segura, porém a literatura é escassa quanto às alterações hematológicas e bioquímicas decorrentes deste procedimento.

O objetivo deste trabalho foi avaliar os efeitos da técnica de biópsia hepática sobre a atividade sérica da aspartato aminotransferase (AST), fosfatase alcalina (FA), gama glutamiltransferase (GGT) e sobre as variáveis do hemograma e fibrinogênio.

\section{MATERIAL E MÉTODOS}

As biópsias hepáticas foram realizadas em 36 novilhas da raça Nelore, com 30 meses de idade e peso médio de $330 \mathrm{~kg}$. O procedimento foi realizado com os animais em estação, contidos em tronco, utilizandose instrumento confeccionado com as seguintes dimensões: comprimento do mandril $25,0 \mathrm{~cm}$, comprimento da cânula $23,0 \mathrm{~cm}$, diâmetro interno da cânula $0,7 \mathrm{~cm}$ e externo $0,8 \mathrm{~cm}$ (Figura 1$)$. A técnica utilizada foi adaptada de SMART \& NORTHCOLE (1985) e McDOWELL (1999), consistindo de anestesia local com lidocaína a $\%$, anti-sepsia com álcool $70^{\circ}$ GL, incisão da pele de $1,5 \mathrm{~cm}$ de extensão com bisturi e penetração da cavidade abdominal com a agulha posicionada na interseção da linha imaginária, traçada paralelamente ao eixo dorsal, partindo do ponto médio da fossa paralombar direita até o $11^{\underline{0}}$ espaço intercostal (Figura 2). Após a penetração da cavidade abdominal, na inserção do diafragma com a parede torácica, o mandril da agulha foi retirado e a cânula deslocada no sentido crânio-ventral, na direção da articulação úmerorádio-ulnar do membro esquerdo. Com movimentos de rosca, a cânula foi introduzida no parênquima hepático. Uma pressão negativa foi produzida, obstruindo-se o orifício externo da cânula com o polegar durante a retirada do conjunto. As amostras foram secas em papel de filtro, pesadas e armazenadas em tubos plásticos de $1,5 \mathrm{~mL}$ à $-20^{\circ} \mathrm{C}$ para análise dos elementos minerais.

Dos animais submetidos à biópsia, 20 foram utilizados para a avaliação da atividade sérica da AST, FA e GGT, sendo divididos em dois grupos. Colheu-se

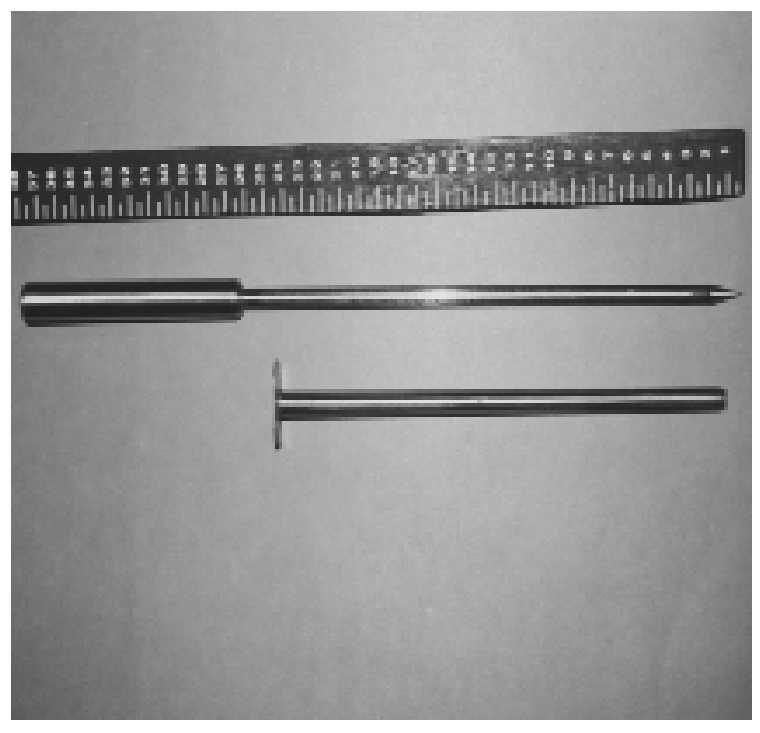

Figura 1 - Agulha de biópsia hepática composta de mandril e cânula. 


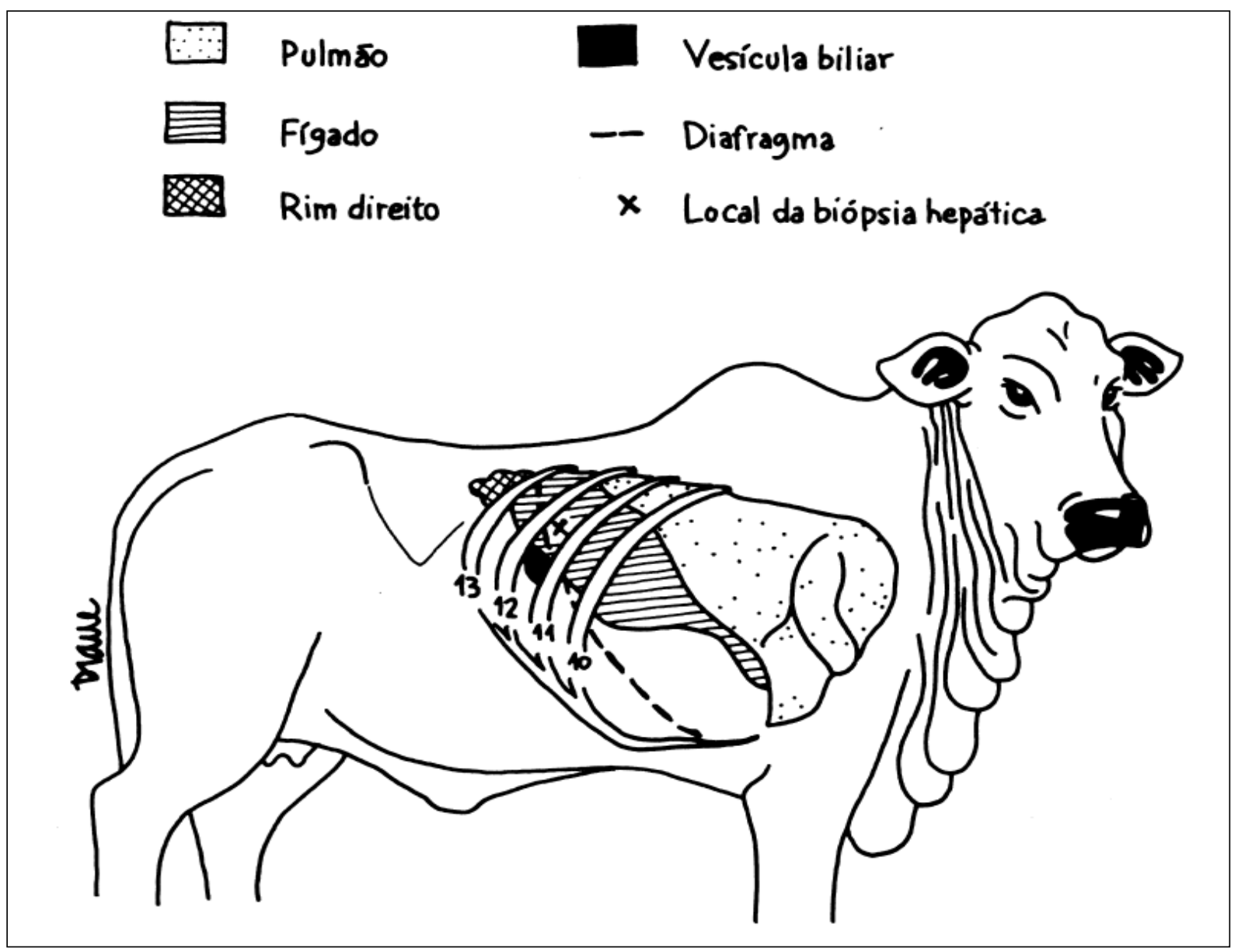

Figura 2 - Local de realização da biópsia hepática em bovinos.

sangue em tubos a vácuo sem anticoagulante do grupo $1(\mathrm{n}=10)$, antes da realização da biópsia e $24 \mathrm{~h}$ após, e do grupo $2(n=10)$ antes da biópsia e 96h após. Para realização do hemograma e determinação do fibrinogênio, o sangue foi colhido em tubos a vácuo com EDTA a $10 \%$ antes e $96 \mathrm{~h}$ após a realização do procedimento $(\mathrm{n}=16)$.

A atividade sérica das enzimas estudadas foi determinada usando-se o método cinético com reagentes bioquímicos comerciais (Analisa ${ }^{\circledR}$ ), sendo a leitura efetuada em espectrofotômetro (Celm SB-190). O hemograma, a contagem de plaquetas e o grau de anisocitose (RDW) foram determinados por um contador automático de células (Cell-Dyn 3500R Abbot). A proteína total e o fibrinogênio foram determinados por refratometria segundo método descrito por JAIN (1993).

Os resultados obtidos foram analisados pelo contraste dos pares das médias entre os momentos, pelo teste t pareado (ZAR, 1984).

\section{RESULTADOS}

A técnica de biópsia hepática realizada neste estudo obteve $100 \%$ de aproveitamento na obtenção do fragmento, com tempo de procedimento em torno de 15 minutos por animal. Os pesos dos fragmentos variaram de 0,6 a $1,8 \mathrm{~g}$. Não foram observadas complicações clínicas nos animais biopsiados. Os resultados da bioquímica sérica, do hemograma, da proteína total e do fibrinogênio estão representados nas tabelas de 1 a 3 .

\section{DISCUSSÃO}

A técnica demonstrou-se segura e eficiente, estando de acordo com as descrições de PEARSON \& CRAIG (1980); SMART \& NORTHCOTE (1985) e NAGARAJAN et al. (1992). As dimensões da agulha de biópsia proporcionaram a obtenção de fragmentos hepáticos com pesos semelhantes aos descritos por 
Tabela 1 - Médias e desvios-padrão da atividade sérica enzimática de 10 novilhas Nelore, antes e $24 \mathrm{~h}$ após a realização da biópsia hepática.

\begin{tabular}{lccc}
\hline Momentos & GGT (UI/L) & AST (UI/L) & FA (UI/L) \\
\hline Antes & $12,6 \pm 6,9^{\mathrm{A}}$ & $103,4 \pm 23,8^{\mathrm{A}}$ & $798,9 \pm 348,2^{\mathrm{B}}$ \\
24h após & $12,8 \pm 12,9^{\mathrm{A}}$ & $159,7 \pm 59,5^{\mathrm{B}}$ & $612,3 \pm 219,4^{\mathrm{A}}$ \\
\hline
\end{tabular}

Médias com letras iguais não diferem significativamente $(\mathrm{p}>0,05)$.

Tabela 2 - Médias e desvios-padrão da atividade sérica enzimática de 10 novilhas Nelore, antes e 96h após a realização da biópsia hepática.

\begin{tabular}{lccc}
\hline Momentos & GGT(UI/L) & AST(UI/L) & FA(UI/L) \\
\hline Antes & $7,3 \pm 2,5^{\mathrm{A}}$ & $87,0 \pm 11,6^{\mathrm{A}}$ & $640,8 \pm 124,5^{\mathrm{A}}$ \\
96h após & $7,8 \pm 3,1^{\mathrm{A}}$ & $91,4 \pm 10,4^{\mathrm{A}}$ & $600,3 \pm 128,3^{\mathrm{A}}$
\end{tabular}

Médias com letras iguais não diferem significativamente $(\mathrm{p}>0,05)$.

Tabela 3 - Médias e desvios-padrão do eritrograma, proteína total, fibrinogênio, plaquetas, RDW e leucograma de 16 novilhas Nelore, antes e $96 \mathrm{~h}$ após a realização da biópsia hepática.

\begin{tabular}{lcc}
\hline & Antes & $96 \mathrm{~h}$ após \\
\hline Hemácias (x 10 $/ \mu \mathrm{L})$ & $8,50 \pm 0,51^{\mathrm{A}}$ & $8,43 \pm 0,52^{\mathrm{A}}$ \\
$\mathrm{Hb}(\mathrm{g} / \mathrm{dL})$ & $13,91 \pm 1,13^{\mathrm{A}}$ & $13,86 \pm 1,10^{\mathrm{A}}$ \\
$\mathrm{VG}(\%)$ & $40,67 \pm 3,58^{\mathrm{A}}$ & $40,26 \pm 3,91^{\mathrm{A}}$ \\
$\mathrm{VCM}(\mathrm{fL})$ & $47,89 \pm 3,12^{\mathrm{A}}$ & $47,74 \pm 3,17^{\mathrm{A}}$ \\
$\mathrm{HCM}(\mathrm{pg})$ & $16,37 \pm 1,02^{\mathrm{A}}$ & $16,46 \pm 1,02^{\mathrm{A}}$ \\
$\mathrm{CHCM}(\%)$ & $34,20 \pm 0,65^{\mathrm{A}}$ & $34,50 \pm 1,5^{\mathrm{A}}$ \\
PT (g/dL) & $8,88 \pm 0,38^{\mathrm{A}}$ & $9,12 \pm 0,59^{\mathrm{B}}$ \\
Fibrinogênio $(\mathrm{mg} / \mathrm{dL})$ & $443,8 \pm 233,7^{\mathrm{A}}$ & $393,8 \pm 165,2^{\mathrm{A}}$ \\
Plaquetas $\left(\times 10^{3} / \mu \mathrm{L}\right)$ & $351,0 \pm 72,2^{\mathrm{A}}$ & $408,2 \pm 138^{\mathrm{A}}$ \\
RDW $(\%)$ & $24,53 \pm 1,34^{\mathrm{A}}$ & $23,98 \pm 1,22^{\mathrm{A}}$ \\
Leucócitos $\left(\times 10^{3} / \mu \mathrm{L}\right)$ & $10,16 \pm 1,17^{\mathrm{A}}$ & $9,48 \pm 1,97^{\mathrm{A}}$ \\
Neutrófilos $\left(\times 10^{3} / \mu \mathrm{L}\right)$ & $3,47 \pm 1,26^{\mathrm{B}}$ & $2,69 \pm 0,87^{\mathrm{A}}$ \\
Linfócitos $\left(\times 10^{3} / \mu \mathrm{L}\right)$ & $5,56 \pm 1,54^{\mathrm{A}}$ & $5,46 \pm 1,20^{\mathrm{A}}$ \\
Monócitos $\left(\times 10^{3} / \mu \mathrm{L}\right)$ & $0,56 \pm 0,17^{\mathrm{A}}$ & $0,76 \pm 0,24^{\mathrm{B}}$ \\
Eosinófilos $\left(\times 10^{3} / \mu \mathrm{L}\right)$ & $0,55 \pm 0,35^{\mathrm{A}}$ & $0,53 \pm 0,22^{\mathrm{A}}$ \\
Basófilos $\left(\times 10^{3} / \mu \mathrm{L}\right)$ & $0,053 \pm 0,085^{\mathrm{A}}$ & $0,044 \pm 0,021^{\mathrm{A}}$ \\
\hline
\end{tabular}

Médias com letras iguais não diferem significativamente $(\mathrm{p}>0,05)$.

$\mathrm{Hb}$ : hemoglobina; VG: volume globular; VCM: volume corpúscular médio; HCM: hemoglobina corpúscular média; CHCM: concentração de hemoglobina corpúscular média; PT: proteína total; RDW: grau de anisocitose

\section{GARNER(1950), MENDES et al. (1982) e McDOWELL} (1999).

As avaliações das atividades séricas enzimáticas, $24 \mathrm{~h}$ após a biópsia, revelaram um aumento significativo $(54,4 \%)$ da AST acima dos valores de referência para a espécie. No grupo coletado, 96h após a biópsia, a atividade da AST não apresentou diferença significativa em relação ao momento antes do procedimento. As outras enzimas estudadas (FA e GGT) não sofreram aumentos significativos $24 \mathrm{~h}$ ou $96 \mathrm{~h}$ após a biópsia. As determinações das atividades séricas dessas enzimas têm sido utilizadas para avaliar a integridade do sistema hepatobiliar (KANEKO et al., 1997). A ausência de alterações, nas atividades séricas da FA e da GGT, demonstra que a técnica de biópsia hepática não causou alteração do fluxo biliar.

Os resultados citados estão em concordância com os achados de SMART \& NORTHCOTE (1985), que observaram o aumento transitório da atividade sérica da AST 3h e 24h após a biópsia, e o retorno aos valores normais $48 \mathrm{~h}$ após. Os resultados permitem inferir que o aumento da atividade sérica da AST, após $24 \mathrm{~h}$, ocorre devido à destruição de hepatócitos durante a biópsia. A lesão hepática não manteve o aumento da atividade sérica da AST, 96h após a biópsia, comprovando ser transitória e de pequena extensão.

Pelo fato da AST não ser um indicador específico de lesão hepática (KANEKO et al., 1997), outros tecidos devem ser considerados na interpretação do aumento da atividade sérica enzimática. A lesão da musculatura torácica, durante a realização da técnica, pode contribuir para essa elevação. Porém, como a extensão da injúria muscular é menor que a hepática, a sua contribuição para o aumento da atividade sérica da AST é pouco significativa (SMART \& NORTHCOTE, 1985).

A manutenção dos valores normais do número de hemácias, da concentração de hemoglobina, do volume globular, das plaquetas e dos índices hematimétricos (VCM, HCM, CHCM e RDW), 96h após o procedimento, demonstra que a biópsia hepática não provocou hemorragia suficiente para causar alteração na hematimetria dos bovinos avaliados. O RDW mede o grau de anisocitose das hemácias, estando freqüentemente aumentado nos casos de anemia, sendo capaz de indicar precocemente a variação do volume globular das hemácias (HARVEY, 1997).

A avaliação do leucograma não revelou leucocitose, porém observou-se diminuição dos neutrófilos e aumento dos monócitos 96h após a biópsia (tabela 3). Em ambos os casos, os valores médios permaneceram dentro do intervalo de normalidade para a espécie (FELDMAN et al., 2000), não alterando a interpretação clínica do leucograma. Embora pouco significativa, a diminuição dos neutrófilos na circulação pode estar relacionada com a migração destas células para o local da lesão tecidual (FELDMAN, et al., 2000). 
Os valores médios de proteína total, antes e após o procedimento, apresentaram-se acima dos valores de referência para a espécie. Observou-se um aumento de $0,24 \mathrm{~g} / \mathrm{dl}, 96 \mathrm{~h}$ após a biópsia. Esse aumento pode ser atribuído, dentre outros, aos fatores nutricionais, ao balanço hídrico e a uma resposta inflamatória à injúria das células musculares esqueléticas e dos hepatócitos provocada pela agulha de biópsia. Nos momentos avaliados, não se observaram diferenças significativas nos valores do fibrinogênio. Entretanto, essa proteína de fase aguda pode ter se elevado e retornado aos valores normais 96h após o procedimento, pois, segundo KANEKO et al. (1997), o fibrinogênio tem meia vida plasmática de aproximadamente $36 \mathrm{~h}$.

\section{CONCLUSÃO}

As pequenas lesões teciduais causadas por esta técnica de biópsia hepática não provocam alterações significativas nas variáveis do hemograma, no fibrinogênio e nas atividades séricas enzimáticas da FA e GGT. A atividade sérica da AST aumenta significativamente $24 \mathrm{~h}$ após a realização da biópsia, mas se mantém dentro dos valores de referência $96 \mathrm{~h}$ após o procedimento. Portanto, os resultados obtidos permitem concluir que a técnica de biópsia hepática empregada é segura e eficaz por não provocar dano hepático extenso e por obter rapidamente fragmentos adequados para análise bromatológica e/ou histopatológica.

\section{REFERÊNCIAS BIBLIOGRÁFICAS}

ANDERSON, T.A. et al. Reliability of the liver biopsy technique for estimating hepatic vitamin A. Am J Anim Sci, v.21, p.369-372, 1962

BONE, J.F. A technique for aspiration liver biopsy in dairy cattle. North Am Vet, v.35, p.747-752, 1954.

BUCKLEY, W.T.; EIGENDORF, G.K.; DORWARD, W.J. A liver biopsy instrument for large animals. Can J Anim Sci, v.66, p.1137-1140, 1986.

CHAPMAN, H.L. et al. Evaluation of the liver biopsy technique for use in mineral nutrition studies with beef cattle. J Anim Sci, v.22, p.733-737, 1963.

DICK, A.T. Aspiration biopsy of the liver in sheep. Austral Vet J, v.20, p.298-303, 1944

ERWIN, E.S. et al. Uses of aspiration biopsy technique. J Anim Sci, v.15, p.428-434, 1956

FELDMAN, B.F.; ZINKL, J.G.; JAIN, N.C. Schalm's veterinary hematology. 5. ed. Philadelphia : Lippincott
Williams \& Wilkins, 2000. 1344p.

FICK, K.R., et al. Methods of mineral analysis for plant and animal tissues. 2. ed. Gainesville : Animal Science Department, University of Florida, 1979. 90p.

GARNER, R.J. Aspiration biopsy liver for the cattle. Vet Rec, v.62, p.729-730, 1950.

HARVEY, J.W. Hematology indices: Diagnostic values and pitfalls, Lake Buena Vista, FL, 1997. In: ACVIM, 15., 1997. Lake Buena Vista, FL. Proceedings... Lake Buena Vista : American College of Veterinary Internal Medicine, 1997. p.79.

HUGHES, J.P. A simplified instruments for obtain liver biopsies in cattle. Am J Vet Res, v.23, n.96, p.1111-1112, 1962.

IVERSEN, P.; ROHOLM, K. On aspiration biopsy of the liver, with remarks on its diagnostic significance. Acta Med Scand v.102, p.1-16, 1939.

JAIN, N.C. Essentials of veterinary hematology. Philadelphia : Lea \& Febiger, 1993. 417p.

KANEKO, J.J.; HARVEY, J.W.; BRUSS, M.L. Clinical biochemistry of domestic animals. 5. ed. San Diego: Academic, 1997. 932p.

LOOSMORE, R.M.; ALLCROFT, R. Technique and use of liver biopsy in cattle. Vet Rec, v.63, p.414-416, 1951.

McDOWELL, L.R. Minerais para ruminantes sob pastejo em regiões tropicais, enfatizando o Brasil. 3. ed. Bannochburn, IL: IMC - Agrico Feed Ingredients, 1999. 92p.

MENDES, M.O. et al. Viabilidade da técnica de biópsia de fígado na determinação dos teores de certos minerais em bovinos. Arq Univ Fed Rur Rio de J, v.5, n.1, p.55-60, 1982.

NAGARAJAN, B. et al. A note on comparative study on liver biopsy site in cattle. Indian Vet J, v.69, n.6, p.573-574, 1992.

PEARSON, E.G.; CRAIG, A.M. The diagnosis of liver disease in equine and food animals. Modern Vet Pract, v.63, n.3, p.233-238, 1980 .

SEGHETTI, L.; MARSH, H. Liver biopsy in cattle. Am J Vet Res, v.14, p.9-11, 1953.

SIMPSON. J.W. A new biopsy needle for use in the diagnosis of liver disease. Vet Rec, v.117, p.639-640, 1985.

SMART, E.; NORTHCOTE, M.J. Liver biopsies in cattle. Comp Cont Educ, v.7, n.5, p.327-332, 1985.

UDALL, R.H.; WARNER, R.G., SMITH, S.E. A liver biopsy technique for cattle. Cornell Vet, v.42, p.25-27, 1952.

WITHEHAIR, C.K.; DA SILVA, R.B.; AMES, N.K. Liver biopsy in cattle. The bovine practioner, n.3, p.144-147, 1988.

ZAR, J.H. Biostatistical analysis. Englewood Clifs : PrenticeHall, 1984. 718p. 